\title{
Percutaneous transcatheter retrieval of misplaced therapeutic embolisation devices
}

\author{
I C Huggon, S A Qureshi, J Reidy, R Dos Anjos, E J Baker, M Tynan
}

\begin{abstract}
Objective-To assess the incidence and subsequent management of misplaced devices as a complication of therapeutic embolisation procedures.

Design-Retrospective review of case notes, cardiac catheterisation reports, and angiograms.

Setting-Tertiary referral centre for congenital heart disease.

Patients-205 consecutive children and adults undergoing therapeutic embolisation for congenital heart disease in the 10 years up to 1 April 1993. This group had 231 therapeutic embolisation procedures at 241 sites using coils, umbrella devices, or detachable balloons.

Main outcome measures-Incidences of misplacement and retrieval of the device; morbidity and mortality.

Results-The incidence of misplacement was $3 \%(10 / 332)$ of devices deployed and $4 \cdot 3 \%(10 / 231)$ of procedures performed. Retrieval from distal pulmonary arteries was not attempted in two patients, but transcatheter retrieval of coils and umbrellas from systemic and pulmonary vessels, using snares or retrieval baskets, was successful in the remaining eight. There were no deaths or serious sequelae related to the procedure, but one patient required femoral arteriotomy for removal of an umbrella device retrieved only as far as the groin. In four of the five most recent cases, the misplaced device was retrieved and the therapeutic embolisation was completed at the same procedure.

Conclusions-Misplacement of a device during therapeutic embolisation is a recognised complication that can be satisfactorily dealt with by transcatheter retrieval without recourse to surgery.
\end{abstract}

Table 1 Summary of all therapeutic embolisation procedures and devices used

\begin{tabular}{lcccl}
\hline $\begin{array}{l}\text { Embolisation } \\
\text { devices }\end{array}$ & $\begin{array}{l}\text { No of } \\
\text { patients }\end{array}$ & $\begin{array}{l}\text { No of } \\
\text { procedures }\end{array}$ & $\begin{array}{l}\text { No of } \\
\text { sites }\end{array}$ & $\begin{array}{l}\text { No of } \\
\text { devices deployed }\end{array}$ \\
\hline Rashkind umbrellas & 177 & 201 & 201 & 201 \\
Coils & 21 & 23 & 32 & 122 \\
Detachable balloons & $8^{\star}$ & $8^{\star}$ & $99^{\star}$ & 9 \\
Total & $205^{\star}$ & $231^{\star}$ & $241^{\star}$ & 332 \\
\hline
\end{tabular}

^ One patient with coronary fistula had both coils and a balloon deployed at the same site.

Paediatric Cardio and Radiology, Guy's

S A Qureshi

J Reidy

R Dos Anjos

$M$ Tynan

Correspondence to:

Department of Paediatric

Cardiology, Guy's Hospital,

Accepted for publication 16 May 1994
For retrieval to be successful it is important to have a wide selection of retrieval equipment available and to be conversant with its use.

(Br Heart f 1994;72:470-475)

Transcatheter retrieval of foreign bodies such as fragments of catheters or guidewires inadvertently released into the cardiovascular system during cardiac catheterisation or the placement of central venous lines is well established and almost always circumvents the necessity for major surgery. ${ }^{12}$ Transcatheter therapeutic embolisation techniques entail the deliberate placement and release of devices within the cardiovascular system to effect the occlusion of an artery or fistula. In congenital heart disease coils, umbrellas, and detachable balloons are the most commonly used devices. Although effective, they have the disadvantage that once passed out from the catheter or released from the delivery system they are potentially irretrievable. They all carry the possible complication of the device becoming misplaced to a site other than that intended. Hence the variety of different types and shapes of foreign bodies that may require retrieval has increased, but modification of transcatheter retrieval techniques has facilitated a high rate of their successful retrieval.

We report our experience over the past $10 \gtreqless$ years in the management of patients in whom $ᄋ$ occlusion devices of various types have become misplaced within the cardiovascular system, and we discuss the techniques and equipment needed for their retrieval. It is crucial for paediatric cardiologists practising transcatheter embolisation to become familiar with retrieval equipment and techniques.

\section{Patients and methods}

Patient and catheterisation laboratory records for the 10 years up to 1 April 1993 were reviewed retrospectively. During this period 231 procedures involving transcatheter implantation of various embolisation devices were carried out in 205 patients with congenital heart disease. Table 1 summarises these procedures. Ten procedures $(4 \cdot 3 \%)$ were complicated by misplacement of the embolisation device, and transcatheter retrieval was attempted in eight of these patients. We report the management of these 10 patients. 
Table 2 Patients with misplaced devices

\begin{tabular}{llllll}
\hline $\begin{array}{l}\text { Case } \\
\text { No }\end{array}$ & Age & Weight $(\mathrm{kg})$ & Diagnosis & $\begin{array}{l}\text { Embolisation } \\
\text { device }\end{array}$ & $\begin{array}{l}\text { Site of } \\
\text { displacement }\end{array}$ \\
\hline 1 & $67 \mathrm{yr}$ & 60 & Right coronary fistula & Detachable balloon & LPA \\
2 & $7 \frac{1}{2} \mathrm{yr}$ & 13.5 & MAPCA & $8 \mathrm{~mm} \mathrm{0.025}$ inch coil & LPA \\
3 & $11 \mathrm{yr}$ & 22.7 & MAPCA & $6 \mathrm{~mm}$ steel coil & RPA \\
4 & $11 \mathrm{yr}$ & 39.5 & Modified Blalock shunt & $\mathbf{8 m m}$ steel coil & LPA \\
5 & $3 \mathrm{yr}$ & 16.2 & Arterial duct & $3 \mathrm{~mm} 0 \cdot 018$ inch platinum coil & Portic bifurcation \\
6 & $3 \mathrm{yr}$ & 13.9 & Arterial duct & $17 \mathrm{~mm}$ umbrella & Aortic bifurcation \\
7 & $10 \frac{1}{2} \mathrm{yr}$ & 47.9 & Arterial duct & $12 \mathrm{~mm}$ umbrella & RPA \\
8 & $10 \mathrm{yr}$ & 28.6 & Arterial duct & $12 \mathrm{~mm}$ umbrella & RPA \\
9 & $20 \mathrm{mnth}$ & 11.3 & Arterial duct & $12 \mathrm{~mm}$ umbrella & LPA \\
10 & $10 \mathrm{yr}$ & 28.6 & Arterial duct &
\end{tabular}

LPA, left pulmonary artery; MAPCA, major aortopulmonary collateral artery; RPA, right pulmonary artery.

Table 3 Results

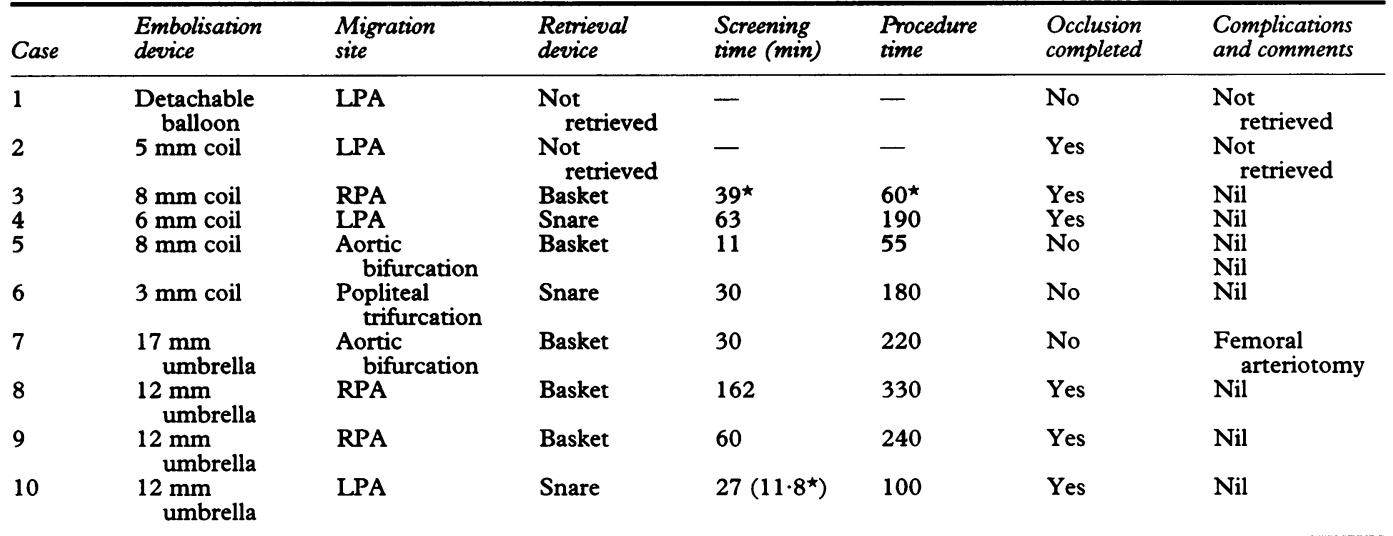

* Transcatheter retrieval only. Other times are for the therapeutic intervention and retrieval combined. LPA, left pulmonary artery; RPA, right pulmonary artery.

\section{RASHKIND DUCT OCCLUDERS}

One hundred and ninety nine Rashkind umbrella devices (Bard USCI) were implanted in the arterial duct in 175 patients,

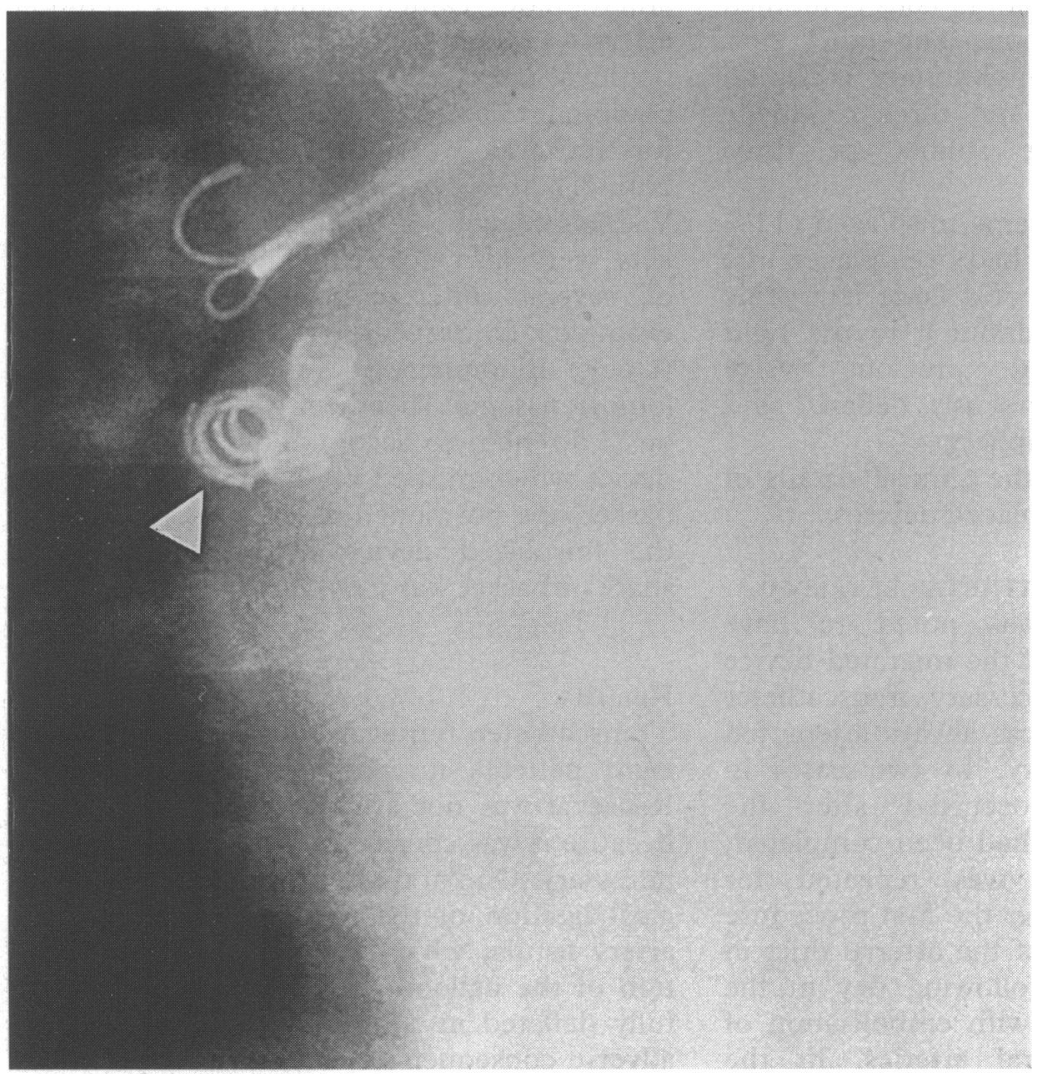

Figure 1 Retrieval of a steel coil placed in an aortopulmonary collateral artery the previous day from the right pulmonary artery in case 3. Note that a transseptal type sheath has been positioned on the right pulmonary artery, which facilitated the passage of the retrieval basket through the right ventricle and outflow tract and protected the basket and coil once they were drawn completely into the sheath. Further coils remain correctly positioned in a collateral artery (arrow). whose median age was $3 \cdot 2$ years (range 7 months to 67 years). Two further Rashkind duct occlusion umbrella devices were implanted without complication in atrial baffle fenestrations after the modified Fontan operation.

In four patients the duct occluder became misplaced almost immediately. Misplacement was to the aortic bifurcation in one patient and to the pulmonary arterial tree in three patients, the device lodging in the right pulmonary artery in one patient and the left pulmonary artery in the two others.

\section{EMBOLISATION COILS}

Twenty one patients (median age 6 years, range 2 months to 50 years) underwent 23 coil embolisation procedures, at which 32 separate sites were treated and 122 coils deployed. The sites treated consisted of nine vessels feeding six coronary artery fistulas, 13 major aortopulmonary collateral arteries in seven patients, one pulmonary arteriovenous malformation, five small patent arterial ducts, and four Blalock-Taussig shunts after their incomplete surgical ligation.

Five embolisation coils became misplaced in five patients ( $4 \%$ of all coils deployed, $16 \%$ of all sites treated). Of these, two were intended for patent arterial ducts, two for major collateral arteries, and one for a residually patent Blalock-Taussig shunt. The misplacement rates for the different sites were thus $40 \%(2 / 5)$ for arterial ducts, $15 \%(2 / 13)$ for major collateral arteries, and $25 \%(1 / 4)$ for Blalock-Taussig shunts with no recorded incidence of misplacement for the coronary fistulas (0/8) or the pulmonary arteriovenous malformation $(0 / 1)$. 


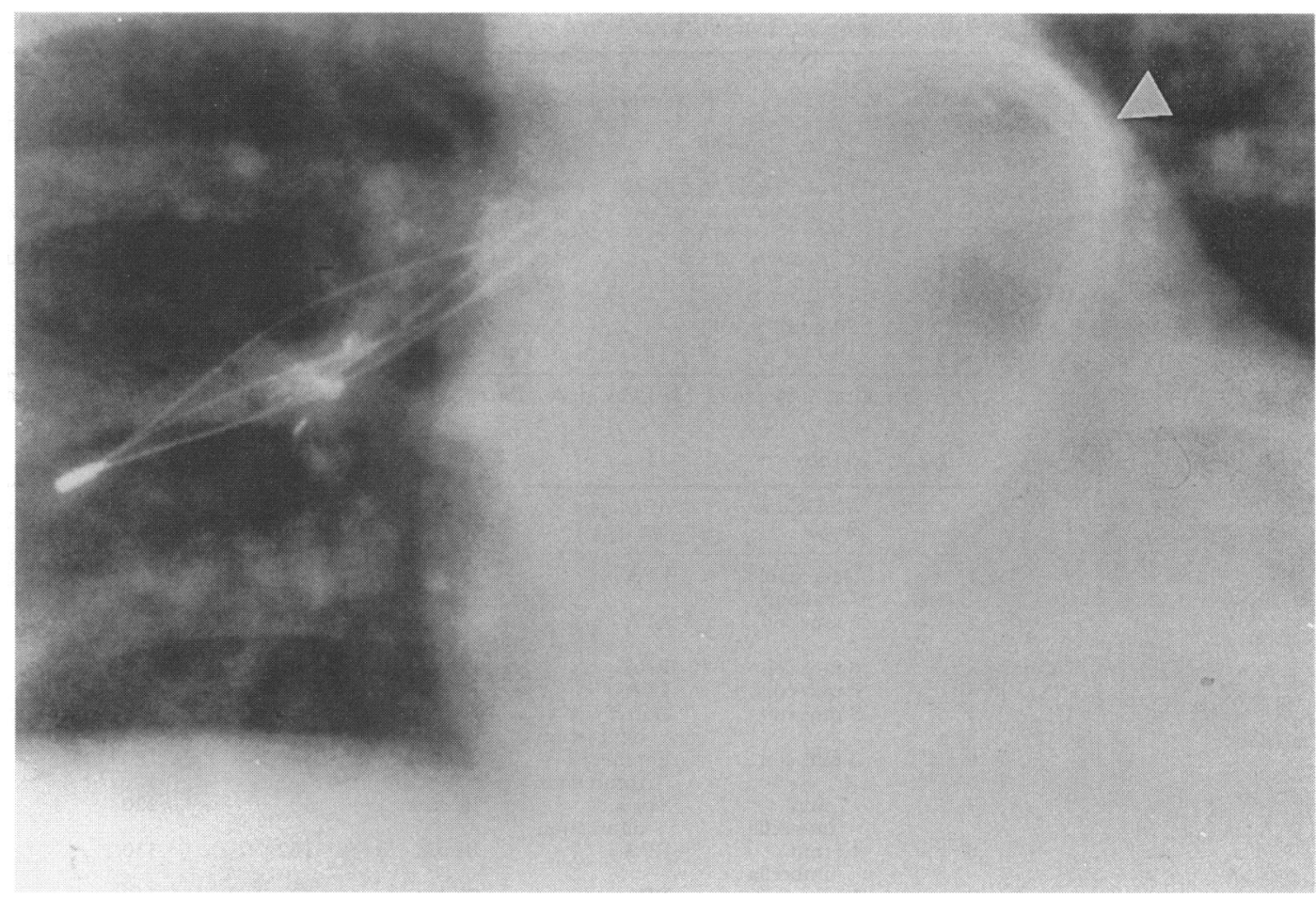

Figure 2 Retrieval of a displaced Rashkind umbrella $(12 \mathrm{~mm})$ in the right pulmonary artery in case 8 by a Dotter basket passed through an 11 French sheath (arrow).

\section{DETACHABLE BALLOONS}

Nine detachable balloons were deployed at nine sites in eight patients, whose median age was 14 years (range 4-67 years). Four balloons were used to embolise four feeding arteries in four coronary fistulas, including one treated with embolisation coils combined with a detachable balloon. The other sites treated were two aortopulmonary collateral arteries in one patient and three residually patent Blalock-Taussig shunts in three patients.

Only one balloon became misplaced (11\% of those deployed). This had been placed in a very short feeder vessel of a large iatrogenic coronary artery fistula draining to the right ventricle (complicating previous valve surgery), but it spontaneously deflated and migrated to the lung periphery.

Table 2 summarises the clinical details of the 10 patients with misplaced devices.

TECHNIQUE FOR TRANSCATHETER RETRIEVAL When misplacement was noted to have occurred and retrieval of the migrated device was considered to be necessary, transcatheter retrieval of the device was always attempted in preference to surgery. In two cases in which misplacement occurred after the embolisation procedure had been completed, cardiac catheterisation was repeated for retrieval immediately after the first procedure for umbrella occlusion of the arterial duct in one case and on the following day in the other case of a patient with embolisation of aortopulmonary collateral arteries. In the remaining six cases the retrieval procedure was a continuation of the initial procedure rather than a separate one. In all cases general anaesthesia was either instituted or continued.
The exact location of the migrated device was established using angiography by hand injection through a suitably positioned angiographic catheter. When necessary, additional vascular access was established. Femoral vessels were used in every case. In one patient, anterograde catheterisation of a femoral artery was required to retrieve a coil from the popliteal artery trifurcation. Table 3 lists the equipment used for retrieval. The snares used for retrieval were commercially produced Nitinol "Gooseneck" snares (Microvena, Vadnais Heights, Minnesota). Retrieval baskets were also commercially produced and of several different styles and sizes-for example, Dotter intravascular retrieval set (Cook, Bloomington, Indiana). Usually, a long transseptal sheath of sufficient gauge (8 or 11 French) to accommodate the migrated device when grasped by the retrieval snare or basket was positioned as close as possible to the misplaced device before the retrieval snare or basket was introduced (fig 1).

\section{Results}

Transcatheter retrieval was successful in all eight patients in whom it was attempted. Retrieval was not attempted in two patients because it was considered neither feasible nor necessary. One of these subsequently had surgical ligation of the feeder to her coronary artery fistula, which had reopened on deflation of the balloon, but the balloon was left fully deflated in the lung periphery with no adverse consequences. In the other patient it was only appreciated several days after the procedure that a $5 \mathrm{~mm}$ coil had migrated to the peripheral lung field from a collateral vessel when a radiograph taken after the procedure was reviewed. The vessel in which this 


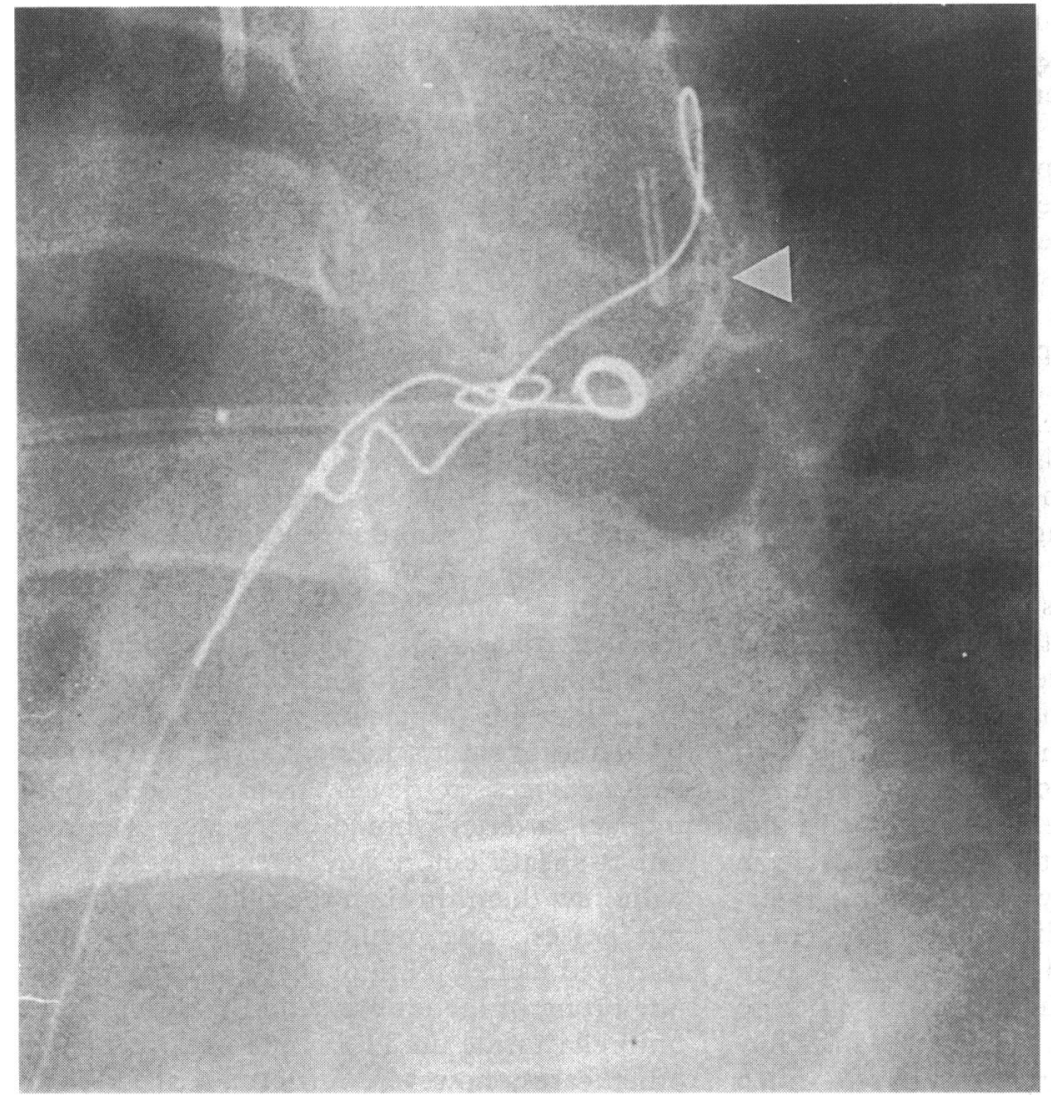

Figure 3 Attempted coil occlusion of a residually patent Blalock shunt after the modified Fontan procedure in case 4. The coil delivery catheter (arrow) remained in place with its tip in the pulmonary arterial end of the shunt but the controlled delivery coil could not be retracted into it. A Nitinol snare introduced through a sheath positioned in the other femoral vein was successful in retrieving the coil and implantation of further coils at the same procedure brought about complete occlusion of the shunt.

coil was lodged remained patent at routine follow up angiography four months later.

The results for the 10 patients with migrated devices are summarised in table 3. Retrieval was achieved using basket type retrieval devices in five patients and with snares in three. There were no deaths or serious complications associated with migrated devices or their retrieval, but one patient required femoral arteriotomy to remove a Rashkind umbrella of $17 \mathrm{~mm}$; this was retrieved only as far as the groin. In this patient the sheath used was too small to allow the umbrella device to be pulled completely inside it.

Two patients had radiological screening times in excess of 60 minutes. In one of these, a Rashkind device of $12 \mathrm{~mm}$ had migrated to a distal branch of the right pulmonary artery. It was difficult to manipulate a catheter into the appropriate branch and subsequently follow it with a suitable long sheath. A large Dotter retrieval basket failed to grasp the device but a small Dotter basket $(5 \mathrm{~cm}$ ) did (fig 2). After retrieval of the migrated device, a Rashkind device was successfully implanted in the arterial duct at the same procedure. The other patient had residual patency of a Blalock shunt after a modified Fontan operation. Occlusion was attempted using a slightly undersized controlled release coil, but there was little narrowing of the shunt against which to lodge the coil. The coil prolapsed out of the shunt into the pulmonary artery when it was beyond the point at which it could be withdrawn into the catheter and had to be retrieved with a snare (fig 3). Subsequently, at the same procedure, coils were successfully lodged in a stable position. It would have been better to occlude this shunt with a detachable balloon.

\section{Discussion}

Although, in our experience, misplacement of embolisation devices was uncommon, it was the most common significant complication occurring in transcatheter embolisation procedures related to the heart. Other workers reported comparable rates of misplacement for similar procedures. ${ }^{34}$ An early extensive review by Bernhardt et al of outcome after migration of foreign bodies within the cardiovascular system suggested that it was a potentially serious complication. ${ }^{5}$ of 62 patients with catheter fragments accidentally embolised to the pulmonary arteries, 17 out of 28 in whom the foreign body was not removed died, but all 34 in whom the foreign body was removed survived. ${ }^{5}$ In a review of 220 cases, including those collected by Bernhardt et al, Fisher and Ferreyro, reached similar conclusions. ${ }^{56}$ There were 16 deaths from sepsis, perforation, arrhythmia, or thrombosis as a direct consequence of the foreign body among the 73 patients in whom removal was not initially attempted, but no deaths related to removal of the foreign body in the remainder. When completeness of follow up was taken into account they estimated a risk of death or serious complication of $71 \%$ in those in whom removal of the foreign body was not initially attempted. Bias towards reporting of eventful cases, limited reports of follow up of those with retained fragments, and difficulties extrapolating outcome from one type of foreign body in a specific group of patients leads us to doubt that the morbidity and mortality from migrated therapeutic embolisation devices left in situ is as high as these reports suggest. Nevertheless, they do emphasise the potential dangers from migrated devices when left in situ. Therefore, every effort should be made to avoid this complication in the first instance, and when it cannot be avoided, retrieval of the foreign body is usually indicated. Transcatheter techniques for retrieval are usually preferable to surgery because the procedure related morbidity is presumed to be less and the location of the foreign body can be monitored throughout the retrieval procedure. There have been several reports of successful retrieval of misplaced guidewire and catheter fragments, including those complicating coronary angioplasty, by transcatheter techniques, ${ }^{1278}$ but no substantial series dealing specifically with interventional procedures in congenital heart disease. Our experience indicates a similar high success rate for retrieval of transcatheter embolisation devices used in and around the heart.

The most appropriate equipment for retrieval of a migrated embolisation device 
depends on the shape and size of the device, the site to which it has migrated, and the experience of the operators with different types of equipment. The ability of the retrieval system to grasp or snare the foreign body is an obvious prerequisite for success. It is also essential that the retrieval system can be manipulated to the site of migration, that it continues to function despite the curves in its length necessary for placement, and that it can be safely withdrawn with the foreign body in its grasp from the site of migration and out through the skin. It is also important to avoid perforating or damaging the cardiovascular system and/or dislodging the foreign body to a less favourable site.

Most retrieval devices fall into one of three categories: snares, retrieval baskets, and grasping forceps. Simple but effective snares can be fashioned by hand from a loop of guidewire threaded through a length of catheter. ${ }^{9}$ Advantages of such home made devices are that they are inexpensive and that the materials to make them are available in every catheter laboratory. However, manufactured snares such as the Nitinol gooseneck snare (Microvena) and similar snares produced by other manufacturers are easier to manipulate in the small vessels to which foreign bodies tend to migrate and have a much smaller gauge (4 French) than the home made equivalent, allowing the use of smaller sheaths. The angulation of the snare loop perpendicular to the shaft of the catheter and their availability in a range of sizes are additional advantages.

Retrieval basket catheters-for example, the Dotter intravascular retrieval set-similar to those used to remove stones from the biliary and urinary systems have been widely used in the cardiovascular system. ${ }^{7}$ Although their profile is generally larger than those of snares, requiring the use of a larger sheath system, they will sometimes grasp objects that cannot be snared with a simple loop. The optimum size and construction of the basket, including the number of wires making up the basket, varies with the individual situation. Occasionally, it will be necessary to try a selection of different baskets before being successful.

Various types of grasping forceps mounted on flexible shafts, the most widely available of which are myocardial biopsy forceps, have been used for transcatheter retrieval..$^{810}$ Because of their sharp surfaces and thick shaft, we have not considered standard myocardial biopsy forceps to be satisfactory for transcatheter retrieval, though others have used grasping forceps specifically designed for this purpose (of which we have no experience). ${ }^{11}$

For the retrieval of coils, especially those made from fine gauge wire, we generally advocate the use of a snare in the first instance because this allows the use of a smaller diameter sheath. Once the snare has been tightened around a free end of the coil, generally there is no difficulty in pulling the coil into the sheath and out of the body.
Where a snare fails, a Dotter basket may prove more successful. Gently twisting the basket in contact with the coil may encourage loops of the coil to pass between the wires of the basket so that they can be grasped.

Rashkind umbrella devices, especially the $17 \mathrm{~mm}$ size, become bulky once opened. Furthermore, the stiff proximal and distal prongs can endanger the vascular endothelium or endocardium if the device is not withdrawn with sufficient care. It is particularly important, if correct positioning is lost, to try to avoid the uncovered device entering the right ventricle and becoming trapped in trabeculations or chordae because open heart surgery will then be required for safe removal. ${ }^{412}$ The right ventricle is one of the most dangerous sites at which a foreign body may lodge. ${ }^{13}$ Therefore it is vital to avoid any possibility of displacing a migrated device from a safer site to the right ventricle. To this end, devices retrieved from branch pulmonary arteries should be pulled securely into a sheath before any attempt is made to withdraw them through the right ventricle. In our series, one umbrella of $12 \mathrm{~mm}$ was retrieved using a Nitinol snare to firmly grasp one prong of the umbrella and pull the whole umbrella inside an 11 French sheath. In the other cases, however, retrieval baskets were used to retrieve Rashkind umbrellas. With a retrieval basket, there are the alternative options of either grasping a single prong of the umbrella device and compressing the device by countertraction from the sheath or of grasping the whole device in the basket and using the basket itself to compress the device and facilitate entry into the sheath.

Before the migrated object is approached with the retrieval instrument, it is important to delineate the surrounding anatomy by angiography. With objects that have migrated to branch pulmonary arteries, there may be considerable difficulty in locating and entering the correct branch, and screening in more than one plane will usually be necessary to achieve this. When possible, and especially at more difficult sites, a long large bore sheath, such as an 11 French or 8 French Mullins transseptal sheath, should be placed, using appropriately shaped catheters and guidewires, close to the object. This has the advantage that the retrieval instrument, which generally has little steerability itself, can be advanced up the sheath to the site of migration. Once the object has been grasped or snared the sheath can be advanced over it, avoiding premature release or damage to the vascular endothelium as it is withdrawn. Alternatively, if as is sometimes the case, it is not possible to advance the sheath over the object, the object may be withdrawn into the sheath. If a large enough sheath can reasonably be used, the retrieved object can be withdrawn through its hub and the vascular access maintained. If, however, it is not feasible to use such a large sheath, it may be necessary to withdraw the sheath and the retrieval instrument and foreign body within it as a whole. In this case, vascular access will be 
lost and it may not be possible to continue with the original procedure. Where only the hub of the sheath prevents complete withdrawal of the retrieval instrument and foreign body, the sheath may be cut at the groin to allow withdrawal and then exchanged over a wire to maintain vascular access. We do not recommend attempting to withdraw the retrieved foreign body through the vessel wall and skin without the protection of a sheath large enough to contain it. Although this has proved satisfactory, but not ideal, for fragments of catheters or wires, ${ }^{714}$ the risk of vascular damage with foreign bodies of more complex shape such as the Rashkind device is likely to be greater.

New devices for placement in the cardiovascular system and modifications of old ones are continually being developed and some of the new developments, such as controlled release mechanisms for embolisation coils relate directly to avoiding the complication of early misplacement. Both the avoidance of misplacement and the ease of transcatheter retrieval should be important design considerations.

\section{CONCLUSION}

The primary strategy for dealing with the problem of migrated embolisation devices should be prevention. However, it seems unlikely that improvements in technique and equipment design can ever eliminate this problem, and those practising transcatheter interventional techniques should have available a range of retrieval devices and know how to use them. Migrated occlusion devices usually need to be recovered and transcatheter retrieval will usually be the most appropriate method.

1 Uflacker R, Lima S, Melichar AC. Intravascular foreign bodies: percutaneous retrieval. Radiology 1986;160: 731-5.

2 Dotter CT, Roesch J, Bilbao MK. Transluminal extraction of catheter and guide fragments from the heart and great vessels; 29 collected cases. AfR Am $\mathcal{F}$ Roentgenol 1971;111:467-72.

3 Perry SB, Rome JR, Keane JF, Baim DS, Lock JE. Transcatheter closure of coronary artery fistulas. $\mathcal{F} \mathrm{Am}$ Coll Cardiol 1992;20:205-9.

4 Hosking MCK, Benson LB, Musewe N, Dyck JD, Freedom RM. Transcatheter occlusion of the persistently patent ductus arteriosus: forty-month follow-up and prevalence of residual shunting. Circulation 1991; 84:2313-7.

5 Bernhardt LC, Wegner GP, Mendenhall JT. Intravenous catheter embolization to the pulmonary artery. Chest 1970;57:329-32.

6 Fisher RG, Ferreyro R. Evaluation of current techniques for nonsurgical removal of intravascular iatrogenic foreign bodies. AfR Am 7 Roentgenol 1978;130:541-8.

7 Grabenwoeger F, Bardach G, Dock W, Pinterits F. Percutaneous extraction of centrally embolized foreign bodies: a report of 16 cases. Br $\mathcal{f}$ Radiol 1988;61: 1014-8.

8 Hartzler GO, Rutherford BD, McConahay DR. Retained percutaneous transluminal coronary angioplasty equipment components and their management. $\mathrm{Am} \mathcal{F} \mathrm{Cardiol}$ 1987;60:1260-4.

9 Hartnell GG. Homemade snare for removal of foreign bodies. Radiology 1991;181:903-4.

10 Bloomfield DA. Technique for nonsurgical retrieval of iatrogenic foreign bodies from the heart. $A m \mathcal{F}$ Cardiol 1971;27:538-45.

11 Selby JB, Tegtmeyer CJ, Bittner GM. Experience with new retrieval forceps for foreign body removal in the vascular, urinary and biliary systems. Radiology 1990; 176:535-8.

12 Transcatheter occlusion of persistent arterial duct: report of the European registry. Lancet 1992;340:1062-6.

13 Richardson JD, Grover FL, Trinkle JK. Intravenous catheter emboli: experience with twenty cases and collective review. Am f Surg 1974;128:722-7.

14 Geraci AR, Selman AW. Pulmonary artery catheter emboli: successful nonsurgical removal. Ann Intern Med 1973;78:353-6. 